\title{
Artikel
}

\section{Enkele opmerkingen over het het una via- beginsel en het nieuwe Wetboek van Strafvordering}

\author{
Mr. dr. drs. B. van der Vorm*
}

\section{Inleiding}

Thans is sprake van een grote wetgevingsoperatie, waarin het Wetboek van Strafvordering wordt gemoderniseerd, zodat het voldoet aan de huidige matstaven. ${ }^{1}$ Apart van dit omvangrijke wetgevingsproject zal het kabinet een nieuwe afweging maken met betrekking tot de toe te passen criteria ten aanzien van de keuze tussen strafrechtelijke en bestuursrechtelijke handhaving. De reden hiervoor is erin gelegen dat de zogenoemde 'open context' en 'besloten context' van verschillende kanten is bekritiseerd ${ }^{2}$ en de wetgever op zoek is naar nieuwe, beter hanteerbare criteria. In het huidige Wetboek van Strafvordering, maar ook in de Awb, zijn regels neergelegd over de samenloop tussen een bestuursrechtelijke boeteprocedure en een strafrechtelijke procedure. Kan ten aanzien van hetzelfde feit, in twee verschillende procedures zowel een bestuurlijke boete als een strafrechtelijke sanctie worden opgelegd? Het antwoord op deze vraag luidt ontkennend. Uit artikel 5:44, eerste lid, Awb, blijkt immers dat het bestuursorgaan geen bestuurlijke boete oplegt indien tegen de overtreder

* Mr. dr. drs. B. van der Vorm is universitair docent straf(proces)recht en is verbonden aan het Willem Pompe Instituut en het Montaigne Centrum voor Rechtspleging en Conflictoplossing van de Universiteit Utrecht. Hij is tevens redacteur van dit tijdschrift.

1. B.F. Keulen, 'Wetboek op stelten. Over de modernisering van het Wetboek van Strafvordering', RMThemis 2014, p. 211-222.

2. Zie bijvoorbeeld A.R. Hartmann, Over de grenzen van de dogmatiek en into fuzzy law (oratie Rotterdam), Apeldoorn/Antwerpen: Maklu 2011, p. 39 e.v. wegens dezelfde gedraging een strafvervolging is ingesteld en het onderzoek ter terechtzitting is begonnen, dan wel een strafbeschikking is uitgevaardigd. Het spiegelbeeld van deze bepaling is te vinden in artikel 243 lid 2 Sv: 'Indien terzake van het feit aan de verdachte een bestuurlijke boete is opgelegd, dan wel een mededeling als bedoeld in artikel 5:50, tweede lid, onderdeel a, van de Algemene wet bestuursrecht is verzonden, heeft dit dezelfde rechtsgevolgen als een kennisgeving van niet verdere vervolging.'

Uit het voorgaande blijkt dat zowel in de Awb als in het huidige Wetboek van Strafvordering het una via-beginsel is neergelegd. Tot op heden is in het verband van 'Modernisering Strafvordering' echter geen enkele aandacht besteed aan deze kwestie en in de Vaststellingswetten, in het bijzonder Boek 3, is het una via-beginsel niet neergelegd. Het huidige artikel 243, tweede lid, Sv, is getransponeerd naar het nieuwe artikel 3.1.4 van het Wetsvoorstel tot vaststelling van Boek 3 van het nieuwe Wetboek van Strafvordering. Uit het eerste lid van laatstgenoemde bepaling blijkt dat na een kennisgeving van niet-vervolging de verdachte niet kan worden vervolgd voor hetzelfde feit, tenzij nieuwe bezwaren bekend zijn geworden of het gerechtshof beklag gegrond verklaart en de opsporing van het feit waarop de klacht betrekking heeft of vervolging van de verdachte beveelt. Hoe dient het ontbreken van een una via-regeling artikel 3.1.4 van het nieuwe Wetboek van Strafvordering te worden gekwalificeerd? Gezien het belang van een dergelijke bepaling ligt het in de rede dat het ontbreken ervan moet worden beschouwd als een omissie. Een nieuwe uitleg van het EHRM over het ne bis in idembeginsel inzake A. en B. tegen Noorwegen zou echter gevolgen kunnen hebben voor de (noodzaak van) codifi- 
catie van een una via-bepaling in het nieuwe Wetboek van Strafvordering. ${ }^{3}$ Tegen deze achtergrond wordt nadere aandacht besteed aan de rol van het una viabeginsel in het nieuwe Wetboek van Strafvordering.

In deze bijdrage staat de volgende onderzoeksvraag centraal: 'Op welke wijze zou een una via-regeling in Boek 3 van het nieuwe Wetboek van Strafvordering gestalte kunnen krijgen?' Om deze onderzoeksvraag te kunnen beantwoorden wordt ten eerste aandacht besteed aan de huidige artikelen 5:44 Awb en 243, tweede lid, Sv (paragraaf 2). Ten tweede wordt het debat over de keuze tussen bestuursrecht en strafrecht besproken met bijzondere aandacht voor de uitleg van het ne bis in idembeginsel door het EHRM (paragraaf 3). Na deze exercitie wordt een voorstel gedaan tot codificering van een una via-regeling in het nieuwe Wetboek van Strafvordering (paragraaf 4). Er wordt afgesloten met een conclusie (paragraaf 5).

\section{Het una via-beginsel in de Awb en het Wetboek van Strafvordering}

\subsection{Inleiding}

Met de opkomst van de bestuurlijke boete als afdoeningsvariant, maar ook door de inwerkingtreding van de Wet OM-afdoening, ${ }^{4}$ is het onderscheid tussen bestuurlijke en strafrechtelijke handhaving er niet eenvoudiger op geworden. ${ }^{5}$ Het una via-beginsel ligt in het verlengde van het ne bis in idem-beginsel. De strekking van dit eerstgenoemde beginsel is dat, indien dezelfde gedraging zowel bestuurlijk als strafrechtelijk kan worden afgedaan, de keuze voor een der wegen op een gegeven moment definitief is. Het una via-beginsel behelst zowel een verbod op dubbele vervolging (Erledigungsprinzip) als op dubbele bestraffing (Anrechnungsprinzip). ${ }^{6} \mathrm{Dit}$ beginsel was voor de inwerkingtreding van de Vierde tranche van de Awb in verschillende bestuursrechtelijke wetten neergelegd. In het commune strafrecht ontbrak een dergelijke bepaling. Het ne bis in idem-beginsel ex artikel $68 \mathrm{Sr}$ ziet namelijk op uitspraken van de strafrechter of afdoeningen binnen de strafrechtelijke sfeer. Met de inwerkingtreding van de Vierde tranche van de Awb is in artikel 243, tweede lid, Sv, de spiegelbepaling van het una via-beginsel van artikel 5:44 Awb neergelegd.

3. EHRM 15 december 2016, BNB 2017/14, m.nt. F.J.P.M. Haas; $A B$ 2017/188, m.nt. T. Barkhuysen \& M.L. van Emmerik.

4. Wet van 7 juli 2006 tot wijziging van het Wetboek van Strafrecht, het Wetboek van Strafvordering en enige andere wetten in verband met de buitengerechtelijke afdoening van strafbare feiten (Wet OM-afdoening), Stb. 2006, 330.

5. Vgl. P.A.M. Mevis, 'Strafbeschikking openbaar ministerie, WAHV en “kleine ergernissen"', DD 2004, p. 353-368; P.A.M. Mevis, 'Bestuurlijke boete in Absurdistan, $A A$ 2005, p, 580-587; T. Kooijmans, ‘De strafbeschikking in verkeerszaken', VR 2007, p. 201-207.

6. L.J.J. Rogier, Strafsancties, administratieve sancties en het una viabeginsel (diss. Rotterdam), Arnhem: Gouda Quint 1992, p. 152 e.v.

\subsection{De strekking van artikel 5:44 Awb}

De Vierde tranche van de Awb is in werking getreden op 1 juli 2009. ${ }^{7}$ In titel 5.4 Awb zijn de artikelen 5:43 en 5:44 Awb neergelegd. De eerstgenoemde bepaling codificeert het ne bis in idem-beginsel voor bestuurlijke boeten. Deze bepaling is het bestuursrechtelijke equivalent van artikel $68 \mathrm{Sr}$. Blijkens artikel 5:43 Awb kan geen bestuurlijke boete worden opgelegd aan de overtreder, indien ter zake van dezelfde overtreding reeds een bestuurlijke boete is opgelegd dan wel het bestuursorgaan na de zienswijze van de overtreder beslist dat de overtreder geen bestuurlijke boete zal worden opgelegd. In artikel 5:44 Awb is het una via-beginsel neergelegd. Volgens het eerste lid van deze bepaling legt het bestuursorgaan geen bestuurlijke boete op, indien tegen de overtreder wegens dezelfde gedraging een strafvervolging is ingesteld en het onderzoek ter terechtzitting is begonnen, dan wel een strafbeschikking is uitgevaardigd. Het is mogelijk dat eenzelfde overtreding zowel een beboetbaar als een strafbaar feit oplevert. Dit feit dient dan te worden voorgelegd aan de officier van justitie, tenzij bij wettelijk voorschrift is bepaald, dan wel met het Openbaar Ministerie is overeengekomen, dat daarvan kan worden afgezien (artikel 5:44, tweede lid, Awb). Het Openbaar Ministerie en het bestuur kunnen in dit verband criteria formuleren onder welke omstandigheden voor de bestuurlijke of de strafrechtelijke afdoening wordt gekozen. Deze criteria dienen te worden neergelegd in een convenant of in de vervolgingsrichtlijnen van het Openbaar Ministerie. De wetgever kan ook zelf criteria formuleren voor de keuze tussen het bestuursrecht en strafrecht. ${ }^{8}$

Uit het derde lid blijkt dat voor een gedraging die aan de officier van justitie moet worden voorgelegd, het bestuursorgaan slechts een bestuurlijke boete oplegt indien de officier van justitie aan het bestuursorgaan heeft medegedeeld ten aanzien van de overtreder van strafvervolging af te zien (artikel 5:44, derde lid, sub a, Awb) of het bestuursorgaan niet binnen dertien weken een reactie van de officier van justitie heeft ontvangen (artikel 5:44, derde lid, sub b, Awb). De situatie kan zich voordoen dat een bestuursorgaan een gedraging aan de officier van justitie voorlegt en binnen de termijn van dertien werken een bestuurlijke boete oplegt zonder dat de officier heeft aangegeven van strafvervolging af te zien. In dergelijke gevallen verliest het Openbaar Ministerie in het belang van de rechtszekerheid van de betrokken burger het vervolgingsrecht. ${ }^{9}$

\subsection{De strekking van artikel 243 , tweede lid, Sv}

\subsubsection{Vervolging megens nieume bezwaren}

Het spiegelbeeld van artikel 5:44 Awb is neergelegd in artikel 243, tweede lid, Sv. De ratio van deze bepaling is

7. Besluit van 25 juni 2009 tot vaststelling van het tijdstip van inwerkingtreding van de Vierde tranche Algemene wet bestuursrecht en de Aanpassingswet vierde tranche Awb, Stb. 2009, 266.

8. Kamerstukken II 2003/04, 29 702, nr. 3, p. 138. Zie voor criteria bijvoorbeeld Kamerstukken I/ 2005/06, 29 849, nr. 30, p. 4-9.

9. Kamerstukken I/ 2003/04, 29 702, nr. 3, p. 139. 
dat, indien een bestuurlijke boete is opgelegd in beginsel strafvervolging niet langer mogelijk is. Thans luidt het tweede lid van artikel $243 \mathrm{~Sv}$ als volgt:

'Indien terzake van het feit aan de verdachte een bestuurlijke boete is opgelegd, dan wel een mededeling als bedoeld in artikel 5:50, tweede lid, onderdeel a, van de Algemene wet bestuursrecht is verzonden, heeft dit dezelfde rechtsgevolgen als een kennisgeving van niet verdere vervolging, met dien verstande dat artikel 245 a niet van toepassing is.'

Met deze bepaling heeft het una via-beginsel zijn intrede gedaan in het Wetboek van Strafvordering. Dit beginsel gaat echter minder ver dan het bestuursrechtelijke equivalent. In tegenstelling tot artikel 5:44 Awb sluit het tweede lid van artikel $243 \mathrm{~Sv}$ niet uit dat na het opleggen van een bestuurlijke boete een strafrechtelijke sanctie plaatsvindt. Dit blijkt namelijk uit de zinsnede 'heeft dit dezelfde rechtsgevolgen als een kennisgeving van niet verdere vervolging.' Blijkens artikel 246, eerste lid, Sv eindigt de zaak door een kennisgeving van nietverdere vervolging. Indien aan de verdachte een kennisgeving van niet-verdere vervolging is betekend, kan hij ter zake van hetzelfde feit niet opnieuw in rechte worden betrokken tenzij nieuwe bezwaren bekend zijn geworden (artikel 255, eerste lid, Sv). In het tweede lid van artikel $255 \mathrm{~Sv}$ is bepaald welke bewijsmiddelen als 'nieuwe bezwaren' kunnen worden gekwalificeerd. Dit zijn verklaringen van getuigen of van de verdachte en stukken, bescheiden en processen-verbaal, welke later zijn bekend geworden of niet zijn onderzocht. Indien sprake is van 'nieuwe bezwaren' kan na oplegging van een bestuurlijke boete alsnog strafvervolging worden ingesteld. Artikel 245a $\mathrm{Sv}$ is niet van toepassing. De memorie van toelichting geeft hierover aan dat de betekening van de kennisgeving voor het bestuursrecht te ver voert. ${ }^{10}$

Het begrip 'nieuwe bezwaren' is gezien de voorgaande formulering zeer ruim. Uiteraard kunnen er na de boeteoplegging nieuwe feiten of omstandigheden naar voren komen, die maken dat - waren zij bekend geweest - tot een strafrechtelijke vervolging hadden geleid. Voorkomen dient wel te worden dat ter behoud van rechten een bestuurlijke boete wordt opgelegd om vervolgens verder te rechercheren en uiteindelijk een strafzaak op te starten.

\subsubsection{Vervolging megens beklagprocedure}

Uit artikel 12l, tweede lid, Sv blijkt dat een kennisgeving van niet-verdere vervolging de toepassing van artikel $12 \mathrm{i}$ Sv niet in de weg staat. Op grond van het eerste lid van artikel 12i Sv kan het gerechtshof bevelen dat de vervolging wordt ingesteld of wordt voortgezet ter zake van het feit waarop het beklag betrekking heeft. Indien door een bestuursorgaan een bestuurlijke boete wordt opgelegd en de officier van justitie hierdoor niet tot vervolging overgaat, kan een rechtstreeks belanghebbende daarover schriftelijk beklag doen bij het gerechtshof (artikel 12, eerste lid, Sv). Het gerechtshof kan dan bevelen dat vervolging ter zake van hetzelfde feit wordt ingesteld. De strafrechter dient, blijkens de memorie van toelichting, in dergelijke gevallen bij de strafmaat rekening te houden met de reeds opgelegde bestuurlijke boete. ${ }^{11}$ De $12 \mathrm{~Sv}$-procedure gaat minder ver dan het thans geldende artikel 5:47 Awb. In deze bepaling is de relatie tussen de bestuurlijke boete en het toepassing geven aan artikel $12 \mathrm{i} \mathrm{Sv}$ geregeld:

'Een bestuurlijke boete die is opgelegd wegens een gedraging die tevens een strafbaar feit is, vervalt indien het gerechtshof met toepassing van artikel $12 \mathrm{i}$ van het Wetboek van Strafvordering de vervolging van de overtreder voor dat feit beveelt.'

Indien een beklagprocedure in de zin van artikel $12 \mathrm{~Sv}$ wordt gestart door een rechtstreeks belanghebbende, beklaagt deze zich over het feit dat een overtreding niet strafrechtelijk wordt vervolgd. Een dergelijke situatie deed zich voor toen een bedrijf op grond van overtreding van het oude artikel 16 lid 10 Arbowet een bestuurlijke boete werd opgelegd. Het betrof hier een arbeidsongeval met dodelijke afloop. De ouders van de overleden persoon waren het niet eens met het afdoen van deze overtreding via dit bestuursrechtelijke traject en zetten een beklagprocedure ex artikel $12 \mathrm{~Sv}$ in. Een belangrijke rol was in dit verband weggelegd voor artikel 33 lid 4 - thans lid 3 - Arbowet. Hieruit blijkt dat geen bestuurlijke boete kan worden opgelegd ter zake van bij of krachtens de Arbowet strafbaar gestelde feiten. De Afdeling Bestuursrechtspraak van de Raad van State (hierna: Afdeling) heeft in dit verband vastgesteld dat een dergelijke overtreding bestuursrechtelijk kan worden afgedaan. Volgens de Afdeling betekent het feit dat sprake is van een arbeidsongeval met dodelijke afloop niet per definitie dat strafrechtelijke vervolging is aangewezen. De Afdeling stelt vast dat in casu een bestuurlijke boete kon worden opgelegd. Ter zake van de ingestelde beklagprocedure overweegt de Afdeling als volgt:

'Voorts is te dezen van gewicht dat appellant eerst na afstemming met het openbaar ministerie heeft besloten dat in dit geval afdoening als beboetbaar feit de geëigende weg was. Bij die afstemming is gebleken dat het openbaar ministerie destijds geen aanleiding zag tot het instellen van een strafrechtelijk onderzoek. Gelet hierop mocht appellant er ten tijde van het nemen van zijn beslissing om tot bestuursrechtelijke handhaving over te gaan van uitgaan dat de situatie als bedoeld in artikel 33, vierde lid, van de Arbowet zich hier niet voordeed. Hieraan doet niet af dat nadien een procedure als bedoeld in artikel 12 van het $\mathrm{WvSv}$ in gang is gezet. Overigens merkt de Afdeling op dat appellant te kennen heeft gegeven gebruik te willen maken van de in artikel 43 van de wet voorzie- 
ne terugbetalingsregeling indien de strafrechter zou komen tot bestraffing ter zake van een strafbaar feit als bedoeld in artikel 33, vierde lid, van de Arbowet, zonder rekening te houden met de opgelegde boete. ${ }^{12}$

Blijkens de Afdeling mocht de appellant ervan uitgaan dat in casu geen sprake was van een situatie zoals bedoeld in artikel 33 lid 4 Arbowet (oud). ${ }^{13}$ De bestuurlijke boete kon derhalve worden opgelegd. Het feit dat de rechtstreeks belanghebbende een beklagprocedure ex artikel $12 \mathrm{~Sv}$ heeft ingesteld, doet hieraan niet af. Met de inwerkingtreding van artikel 5:47 Awb is dit veranderd. Indien de vervolging op grond van artikel $12 \mathrm{i} \mathrm{Sv}$ door het gerechtshof wordt bevolen, vervalt de opgelegde bestuurlijke boete. Dit geldt ook indien de bestuurlijke boete reeds onherroepelijk is geworden. Als een bestuurlijke boete door de overtreder is betaald, dient dit bedrag door het bestuursorgaan te worden terugbetaald. ${ }^{14}$

\subsection{Enige bijzondere una via-regelingen}

2.4.1. De ernst van de gedraging als mettelijk criterium De una via-bepalingen, zoals deze zijn geformuleerd in de artikelen 5:44 Awb en 243, tweede lid, Sv, zijn formeel van aard. De keuze tussen bestuurlijke of strafrechtelijke handhaving wordt bepaald an de hand van procedurele aspecten. Er bestaan eveneens bepalingen die daarnaast ook materiële aspecten bevatten. Het betreffen de volgende una via-bepalingen: artikel 55 Meststofwet, artikel 7.6 lid 5 Wet natuur, artikel 18.16d Wet milieubeheer, artikel 120g Gezondheids- en welzijnswet voor dieren, artikel 8.10 Wet dieren, artikel 94 Wet gewasbeschermingsmiddelen en biociden en artikel 7 lid 5 Wet implementatie Nagoya Protocol. Al deze regelingen hebben met elkaar gemeenschappelijk dat zij een belangrijk materieel aspect bevatten. Ter illustratie kan worden gewezen op het bepaalde in artikel $18.16 \mathrm{~d}$ Wet milieubeheer:

'Indien de gedraging tevens een strafbaar feit is en de ernst van de overtreding of de omstandigheden waaronder zij is begaan daartoe anleiding geven, legt het bestuur van de emissieautoriteit haar an het openbaar ministerie voor.'

Uit deze bepaling blijkt dat wanneer een gedraging zowel een beboetbaar feit als een strafbaar feit oplevert, de gedraging moet worden voorgelegd aan het Openbaar Ministerie. In die zin vertoont het bepaalde in artikel 18.16d Wet milieubeheer overeenkomst met artikel 5:44, tweede lid, Awb. Artikel 18.16d Wet milieubeheer gaat echter verder, omdat ook rekening moet worden gehouden met de ernst van de overtreding. Bij de keuze tussen bestuursrechtelijke handhaving en strafrechtelijke handhaving speelt het criterium van de ernst van de

12. ABRvS 10 september 2003, AB 2004/324; JB 2003/310.

13. Blijkens dit lid kan geen bestuurlijke boete worden opgelegd ter zake van bij of krachtens de Arbowet strafbaar gestelde feiten.

14. Kamerstukken // 2003/04, 29 702, nr. 3, p. 145. overtreding een rol, hetgeen door de wetgever is onderkend. Volgens de wetgever is de inzet van het strafrecht gereserveerd voor ernstige overtredingen. ${ }^{15}$ Het strafrecht wordt aldus opgevat als ultimum remedium.

\subsubsection{Een discussie over de voorlegplicht van de artikelen 5:44 Amb en 55 Meststoffenmet}

De keuze tussen bestuurlijke of strafrechtelijke handhaving kan leiden tot discussie. In dit verband wordt gewezen op de voorlegplicht van artikel 5:44, tweede lid, Awb en 55 Meststoffenwet. ${ }^{16}$ Een belangrijke vraag is in hoeverre een belanghebbende een beroep kan doen op de afstemmingsregels die zijn neergelegd in artikel 5:44, tweede en derde lid, Awb. In casu was aan de betrokkene een bestuurlijke boete opgelegd wegens overtreding van de Meststoffenwet. Deze gedraging is echter door de staatssecretaris van Economische Zaken niet voorgelegd aan het Openbaar Ministerie, terwijl daar volgens de betrokkene wel aanleiding toe was. De grote kamer van College van Beroep voor het bedrijfsleven heeft A$G$ Keus verzocht om een conclusie ten aanzien van de verhouding tussen strafrechtelijke handhaving en bestuurlijke handhaving, als neergelegd in het bepaalde in artikel 5:44, tweede en derde lid, van de Awb en de mogelijke consequentie(s) voor het boete-opleggende bestuursorgaan ingeval niet in overeenstemming met het bepaalde in artikel 5:44, tweede en derde lid, van de Awb is gehandeld. A-G Keus concludeert onder andere dat artikel 5:44, tweede en derde lid, Awb, op grond van de wetsgeschiedenis kennelijk niet strekt tot bescherming van de belangen van de (mogelijke) overtreder. Ook concludeert hij dat 'op grond van de wetsgeschiedenis moet worden aangenomen dat het veronachtzamen van de voorlegplicht door het bestuursorgaan niet tot onbevoegdheid van het bestuursorgaan leidt, en dat de bevoegdheid tot bestuurlijke boeteoplegging eerst wordt opgeschort, nadat de gedraging die tevens een strafbaar feit is, daadwerkelijk an de OvJ is voorgelegd. ${ }^{17}$ Deze conclusies worden overgenomen door het College van Beroep voor het bedrijfsleven. ${ }^{18}$ Het College van Beroep voor het bedrijfsleven overweegt in rechtsoverweging 7.1 als volgt:

'Blijkens de geschiedenis van de totstandkoming van de Wet aanpassing bestuursprocesrecht (Kamerstukken II, 2009-2010, 32 450, nr. 3, blz. 18-20) heeft de wetgever met artikel 8:69a van de Awb de eis willen stellen dat er een verband moet bestaan tussen een beroepsgrond en het belang waarin de appellant door het bestreden besluit dreigt te worden geschaad. De bestuursrechter mag een besluit niet vernietigen wegens schending van een rechtsregel die kennelijk niet strekt tot bescherming van de belangen van de appellant. Zoals de raadsheer advocaat-generaal

15. Kamerstukken // 2006/07, 31 124, nr. 3, p. 80.

16. Artikel 55 Meststoffenwet luidt als volgt: 'Indien de ernst van de overtreding of de omstandigheden waaronder zij is begaan daartoe aanleiding geven, wordt zij aan het openbaar ministerie voorgelegd.'

17. CBb 8 mei 2017, ECLI:NL:CBB:2017:130

18. CBb 26 oktober 2017, AB 2017/430, m.nt. R. Stijnen. 
onder 5 in zijn conclusie heeft uiteengezet - welke uiteenzetting het College volgt - doet de geschiedenis van de totstandkoming van artikel 5:44 van de Awb zien dat de regeling van het tweede en derde lid van dat artikel kennelijk niet strekt tot bescherming van de belangen van de (mogelijke) overtreder. Datzelfde geldt, naar uit voormelde conclusie evenzeer kan worden afgeleid, ook met betrekking tot artikel 55 van de Msw, bezien in het licht van de totstandkoming van dat artikel. Evenmin is gebleken van feiten of omstandigheden die dwingen tot het oordeel dat het gebrek aan relativiteit hier zou moeten worden gecorrigeerd door toepassing van (kortweg) de bestuursrechtelijke pendant van de zogenoemde "correctie-Langemeijer". Ook op dat punt aansluitend bij de conclusie van de radsheer advocaat-generaal, is het College op basis van het voorgaande van oordeel dat al hetgeen appellant in dit verband ter bestrijding van de aangevallen uitspraak heeft angevoerd, in de kern ertoe strekkende dat de staatssecretaris niet bevoegd was om in het onderhavige geval een boete op te leggen, buiten verdere bespreking kan blijven.'

Annotator Stijnen kan zich vinden in de uitspraak van het College van Beroep voor het bedrijfsleven. Hij geeft aan dat de strekking van de una via-regeling is om te voorkomen dat er niet tweemaal wordt vervolgd en bestraft. Er was in casu volstaan met de oplegging van een bestuurlijke boete, waardoor het una via-beginsel als zodanig niet in geschil was. ${ }^{19}$ Voorts kan Stijnen instemmen met de beslissing dat de bestuursrechtelijke tegenhanger van de 'correctie-Langemeijer' - of: de correctie Widdershoven ${ }^{20}$ - hier geen soelaas biedt, omdat geen geslaagd beroep kan worden gedaan op het vertrouwensbeginsel en het gelijkheidsbeginsel. Zoals Stijnen opmerkt, volstaan verwachtingen ontleend aan een algemene formele handeling in dit verband niet. ${ }^{21}$

Het voorgaande betekent niet dat de uitspraak van het College van Beroep voor het bedrijfsleven niet vrij is van commentaar. Vóór het verschijnen van de uitspraak van het College van Beroep voor het bedrijfsleven zijn door Rogier twee kanttekeningen geplaatst bij de conclusie van A-G Keus. Ten eerste wordt door Rogier opgemerkt dat de A-G het probleem aan de hand van de wetsgeschiedenis heel technisch opvat en de bestuurlijke en strafrechtelijke handhavingsmiddelen als gelijksoorti-

19. Zie de vijfde opmerking in de annotatie van R. Stijnen onder CBb 26 oktober 2017, AB 2017/430.

20. De correctie Widdershoven houdt in dat rechter de toepassing van artikel 8:69a Awb dient te corrigeren in die zin dat de schending van een norm die niet de bescherming beoogt van de belangen van een belanghebbende, en die op zichzelf genomen dus niet tot vernietiging zou kunnen leiden, kan bijdragen tot het oordeel dat het vertrouwensbeginsel of gelijkheidsbeginsel is geschonden. Zie ABRvS 16 maart 2016, AB 2016/249, m.nt. T.E.P.A. Lam, waarin de Afdeling de correctie voor de eerste keer heeft aanvaard. Vgl. K.J. de Graaf \& G.A. van der Veen, 'De correctie Widdershoven gewogen', NTB 2016, p. 169-176; W. Konijnebelt, 'Een correctie op het relativiteitsvereiste van 8:69a Awb? De conclusie-Widdershoven in de zaak plan Blaloweg en Katwolderweg Zwolle', NTB 2016, p. 159-162

21. Zie de zesde opmerking in de annotatie van R. Stijnen onder CBb 26 oktober 2017, AB 2017/430 ge instrumenten lijkt te beschouwen. Naar zijn mening is het bestuur, dat de voorlegplicht niet naleeft, niet bevoegd om zelf een bestuurlijke boete op te leggen. Het bestuur bepaalt immers niet welke gedraging wel en welke niet wordt voorgelegd aan het Openbaar Ministerie. Het primaat ligt onder dergelijke omstandigheden bij het Openbaar Ministerie. Met andere woorden: indien een gedraging zowel een beboetbaar als een strafbaar feit oplevert, is het bestuur verplicht om deze gedraging voor te leggen aan het Openbaar Ministerie. ${ }^{22}$ Ten tweede wijst Rogier op de rechtsbeschermende functie van de artikelen 5:44 Awb en 55 Meststoffenwet. Indien het bestuur de voorlegplicht veronachtzaamd en een bestuurlijke boete oplegt, wordt de betrokkene een oordeel van het Openbaar Ministerie en eventueel de strafrechter, ontnomen. Dit levert volgens Rogier strijd op met het ius de non evocando. Naar zijn mening dient een verdachte, die ook door het bestuur bestuurlijk beboet kan worden, niet de kans te mogen worden onthouden op een oordeel van de strafrechter. ${ }^{23}$

Uit het voorgaande blijkt dat de problematiek van de niet-naleving van de voorlegplicht van het bestuur vooral betrekking heeft op de eventuele rechtsgevolgen van een dergelijke niet-naleving. De A-G baseert zijn conclusie op de wetsgeschiedenis en die analyse laat zien dat het niet voorleggen van een gedraging dat zowel een beboetbaar feit als een strafbaar feit oplevert, kennelijk niet leidt tot de onbevoegdheid van het bestuursorgaan om een bestuurlijke boete op te leggen. Het is vervolgens de vraag wat de gevolgen van deze visie zijn voor de houdbaarheid van de voorlegplicht. De uitspraak van het College van Beroep voor het bedrijfsleven kan ertoe leiden dat de voorlegplicht van artikel 5:44, tweede lid, Awb, een illusoir karakter krijgt, waardoor het bestuur de mogelijkheid krijgt om gedragingen die een beboetbaar feit en strafbaar feit inhouden, buiten het gezichtsveld van het Openbaar Ministerie te houden en zelf te sanctioneren middels de bestuurlijke boete. Met deze uitspraak van het College van Beroep voor het bedrijfsleven wordt de mogelijkheid geschapen om het Openbaar Ministerie buitenspel te kunnen zetten zonder dat hier consequenties aan worden verbonden.

\section{Het debat over de keuze tussen bestuursrecht en strafrecht}

\subsection{Het ongevraagde advies van de Afdeling advisering van de Raad van State}

Op 13 juli 2015 heeft de Afdeling advisering van de Raad van State (hierna: Afdeling advisering) in een ongevraagd advies aandacht gevraagd voor de rechtsbe-

22. L.J.J. Rogier, 'Bedenkingen bij een Conclusie van AG Keus', NJBlog 28 september 2017.

23. L.J.J. Rogier, 'Bedenkingen bij een Conclusie van AG Keus', NJBlog 28 september 2017. 
scherming van de burgers inzake de oplegging van bestuurlijke boetes. De Afdeling advisering merkt in dit verband op dat zware overtredingen worden bedreigd met hoge bestuurlijke boetes en dat op relatief lichte feiten eveneens hoge boetes zijn gesteld. Ook wijst de Afdeling advisering erop dat de wetgever op grond van efficiencyoverwegingen de keuze maakt aan de hand van de 'open context' en 'besloten context', maar onvoldoende rekening wordt gehouden met de rechtsbescherming van de justitiabele. Middels dit ongevraagde advies vraagt de Afdeling advisering aandacht voor deze kwestie, waarbij de regering opnieuw naar het niveau van de rechtsbescherming bij de oplegging van bestuurlijke boetes zou moeten kijken. Afstemming tussen strafrecht en bestuursrecht met betrekking tot de geregelde rechtsbescherming en de positie van de justitiabele wordt hierbij door de Afdeling advisering wenselijk geacht. Deze afstemming zou in de ogen van de Afdeling advisering moeten leiden tot een verzwaring van het rechtsbeschermingsniveau ter zake van het bestraffende bestuursrecht. Ook wijst de Afdeling advisering erop dat het strafrecht en het bestuursrecht niet als onderling inwisselbaar moeten worden geacht. ${ }^{24}$ Ten aanzien van de keuze tussen bestuursrecht en strafrecht wordt door de Afdeling advisering een voorzet gegeven, namelijk de grens van de vijfde boetecategorie van het Wetboek van Strafrecht. Dit betekent dat wanneer de wens bestaat om hoge boetes op te leggen, gekozen zou moeten worden voor het strafrecht. ${ }^{25}$

\subsection{Opvattingen over de keuze tussen bestuursrecht en strafrecht}

\subsubsection{Tmee visies op de keuze tussen bestuursrecht en strafrecht}

Grosso modo bestaan in de literatuur twee visies op het gewenste criterium ten aanzien van de keuze tussen bestuursrecht en strafrecht. Enerzijds wordt gewezen op de ernst van de gedraging. In deze visie zou het strafrechtelijke traject moeten worden gereserveerd voor ernstige gedragingen. Het strafrecht wordt in deze visie beschouwd als ultimum remedium. Een belangrijke representant van deze visie is Rogier. ${ }^{26}$ Anderzijds wordt het belang van een efficiënte rechtshandhaving benadrukt. Naar de mening van Hirsch Ballin dient het debat niet te zijn gericht op de keuze tussen bestuursrecht en strafrecht, maar vooral hoe vanuit het oogpunt van een efficiënte bestrijding van misdaad, de rechtshandhaving en sanctionering kan worden geïntegreerd. In deze visie wordt het strafrecht opgevat als optimum remedium.

24. Advies van de Afdeling advisering van de Raad van State aan de Minister van Veiligheid en Justitie inzake sanctiestelsels, Stcrt. 14 september 2015, nr. 30280, p. 1

25. Advies van de Afdeling advisering van de Raad van State aan de Minister van Veiligheid en Justitie inzake sanctiestelsels, Stcrt. 14 september 2015, nr. 30280, p. 12.

26. L.J.J. Rogier, Bestuursrecht of strafrecht. Instrumentaliteit of moraliteit? (Afscheidsrede Rotterdam), Den Haag: Boom Juridische uitgevers 2014; B. van der Vorm, 'Bespiegelingen over de keuze tussen bestuursrecht en strafrecht', RegelMaat 2017, p. 336-348.

\subsubsection{Het criterium van de ernstige gedraging}

Ten aanzien van de keuze tussen strafrecht en bestuursrecht speelt doelmatigheid in de opvatting van Rogier geen prominente rol. Hij geeft in zijn afscheidsrede aan dat de wetgever zich bij de keuze tussen bestuursrecht of strafrecht vooral laat leiden door een instrumentele visie. Hiermee bedoelt Rogier dat het recht wordt opgevat als een middel dat de overheid ten dienste staat om zo doeltreffend en zo doelmatig mogelijk ongewenst gedrag te bestrijden. ${ }^{27}$ Rogier vraagt meer aandacht voor de ernst van de gedraging als keuzecriterium. Dit vangt hij onder de term 'moraliteit', waarmee hij bedoelt dat over het ongewenste gedrag een ethisch waardeoordeel wordt geveld. ${ }^{28}$ Aan de hand van drie handhavingsterreinen - de prostitutie, de drugs en het verkeer - concludeert Rogier dat indien sprake is van ernstige gedragingen het primaat ligt bij de strafrechtelijke handhaving en niet bij het bestuursrecht. Weliswaar kan het bestuur in preventieve zin een belangrijke bijdrage leveren aan de bestrijding van onrecht, maar justitie zou bij ernstige gedragingen 'meer zijn tanden moeten laten zien' en het optreden niet moeten overlaten aan het bestuur. Zo zou het intrekken van vergunningen in de prostitutiesector - indien sprake is van ernstige gedragingen - geheel en uitsluitend bij justitie en de strafrechter dienen te liggen. ${ }^{29} \mathrm{Op}$ deze wijze wordt het strafrecht gereserveerd voor ernstige gedragingen en overtredingen en kan het bestuursrecht worden ingezet ten aanzien van minder ernstige overtredingen.

\subsubsection{Efficiency: de geïntegreerde benadering}

Hirsch Ballin kan zich niet vinden in het criterium van de ernstige gedraging en stelt dat het debat over de keuze tussen bestuursrecht en strafrecht ons niet veel verder brengt. Een belangrijke rol is volgens Hirsch Ballin in dit verband weggelegd voor de uitspraak van het EHRM inzake A. en B. tegen Noorwegen, waarin een nieuwe uitleg van het ne bis in idem-beginsel wordt gegeven. Waarin wijkt deze uitspraak nu precies af van eerdere jurisprudentie van 'Europa' over dit onderwerp? En hoe is deze uitspraak van invloed op het debat ten aanzien van de keuze tussen bestuursrecht en strafrecht?

\subsubsection{Belangrijke uitspraken van het EHRM over 'hetzelfde feit'}

Het Zolotukhin-arrest is een van de drie belangrijke arresten van het EHRM over de betekenis van 'hetzelfde feit', die hier nader worden uitgediept. In het Zolotukhin-arrest was de klager meegenomen naar het politiebureau, omdat hij zijn vriendin een militaire basis had binnengesmokkeld. $\mathrm{Na}$ zich op het politiebureau opstandig te hebben gedragen, werd hij direct naar een administratiefrechtelijke rechtbank gebracht en per omgaande veroordeeld wegens verstoring van de openbare orde. Vervolgens werd hij angeklaagd wegens de overtreding van bepalingen uit het Russische Wetboek van Strafrecht. Hij werd vrijgesproken voor de overtreding van het ver-

$\begin{array}{ll}\text { 27. } & \text { Rogier } 2014, \text { p. } 15 . \\ \text { 28. } & \text { Rogier } 2014, \text { p. } 16 . \\ \text { 29. } & \text { Rogier } 2014, \text { p. } 33 .\end{array}$ 
storen van de openbare orde wegens gebrek aan bewijs, maar werd wel strafrechtelijk veroordeeld wegens het beledigen en bedreigen van ambtenaren. Uit dit arrest blijkt dat 'hetzelfde feit' uit artikel 4 van het Zevende Protocol bij het EVRM zo moet worden uitgelegd dat een tweede vervolging of sanctieoplegging niet mogelijk is voor zover deze voortvloeit uit dezelfde feiten of wezenlijk dezelfde feiten. Het komt neer op de vraag of sprake is van samenhangende feiten, die moeten worden bewezen gelet op de delictsomschrijving.

In het Ruotsalainen-arrest ${ }^{30}$ - een fiscale casus - past het EHRM wederom het 'feitelijke' criterium toe. Er is sprake van 'hetzelfde feit' indien gesproken kan worden van identical facts or facts that are substantially the same'. Ruotsalainen kreeg in eerste instantie een 'summary penal order' (soort transactie/strafbeschikking) van $€ 121$ wegens een fiscaal bagateldelict, welke boete hij betaalde. Vervolgens kreeg hij een naheffingsaanslag accijns, waarbij de te heffen belasting met drie werd vermenigvuldigd. Het EHRM stelde vast dat de laatste sanctie weliswaar een administratieve maatregel was, maar dat dit onderdeel wel een 'criminal connotation' had. Hoewel voor het fiscale delict nog wel een vorm van opzet of schuld nodig was en voor de naheffing met verhoging niet, oordeelt het EHRM toch dat de feiten substantieel hetzelfde zijn.

Ten slotte kan worden gewezen op het Maresti-arrest. ${ }^{31}$ Ook in deze zaak past het EHRM het nieuwe feitelijke criterium toe om te beoordelen of sprake is van 'hetzelfde feit' zoals bedoeld in artikel 4 van het Zevende Protocol. De verdachte werd veroordeeld wegens het verstoren van de openbare orde. Onder invloed van alcohol beledigde de verdachte een persoon genaamd D.R. en vervolgens mishandelde hij deze persoon. Dit leverde een 'minor offence' op wegens overtreding van artikel 6 van de 'Minor Offences against Public Order and Peace Act'. De verdachte werd wegens de mishandeling van D.R. ook strafrechtelijk vervolgd en veroordeeld wegens overtreding van artikel 99 'Criminal Code'. De verdachte stelde onder andere dat artikel 4 van het Zevende Protocol bij het EVRM was geschonden. Het EHRM overweegt in r.o. 63 als volgt:

'As to the present case the Court notes that in respect of the minor offence and the criminal offence the applicant was found guilty of the same conduct on the part of the same defendant and within the same time frame. In this connection, it notes that the definition of the minor offence under section 6 of the Minor Offences against Public Order and Peace Act does not as such include inflicting bodily injury while this element is crucial for the criminal offence of inflicting grievous bodily injury under Article 99 of the Criminal Code. However, in its decision, the Pazin Minor-Offences Court expressly stated that the applicant was guilty of, inter alia, hitting D.R. on the head with his fists and of punching and kicking him

30. EHRM 16 juni 2009 Ruotsalainen t. Finland, appl.nr. 13079/03

31. EHRM 25 juni 2009 Maresti t. Kroatië, appl.nr. 55759/07. about his entire body. The physical attack on D.R. thus constituted an element of the minor offence of which the applicant was found guilty. In the criminal proceedings before the Municipal Court the applicant was again found guilty of, inter alia, hitting D.R. The events described in the decisions adopted in both sets of proceedings took place at the Pazin coach terminal at about 7 p.m. on 15 June 2006. It is obvious that both decisions concerned exactly the same event and the same acts.'

Volgens het EHRM is sprake van 'hetzelfde feit' als sprake is van identieke feiten of feiten die wezenlijk hetzelfde zijn. Ook in de Maresti-zaak is het EHRM van oordeel dat sprake is van 'hetzelfde feit' en komt uiteindelijk unaniem tot het oordeel dat het ne bis in idembeginsel is geschonden, aangezien sprake is van een tweede vervolging wegens 'hetzelfde feit' (r.o. 64). Uiteraard zijn verstoring van de openbare orde en mishandeling wezenlijk verschillende feiten en hoeft het een niet samen te gaan met het ander. De reden dat het EHRM de tweede vervolging verbiedt dient mijns inziens dan ook met name te worden gevonden in r.o. 63. In de strafmotivering van het vonnis ter zake van de ordeverstoring, betrekt de rechter tevens de mishandeling. Hieruit lijkt het EHRM af te leiden dat het 'tweede' feit heeft meegewogen bij de strafoplegging van het eerste feit.

3.2.3.1.1.De inhoud van 'hetzelfde feit' blijkens jurisprudentie van het Hof van Justitie EU

Het EHRM heeft bij de formulering van 'hetzelfde feit' in Zolotukhin-arrest aansluiting gezocht bij de rechtspraak van het Hof van Justitie EU over artikel 54 SUO. In het Van Esbroeck-arrest heeft het Hof van Justitie EU aangegeven wanneer sprake is van 'dezelfde feiten' zoals bedoeld in artikel 54 SUO. ${ }^{32}$ Deze term omvat 'een geheel van feiten die onlosmakelijk met elkaar verbonden zijn, ongeacht de juridische kwalificatie van deze feiten of het beschermde rechtsbelang'. ${ }^{33}$ Uit deze omschrijving blijkt dat de juridische kwalificatie van een gedraging niet relevant is bij de beoordeling of sprake is van 'hetzelfde feit'. Er dient aldus sprake te zijn van 'objectieve, historische feiten' ${ }^{34}$ Het Hof van Justitie heeft 'Van Esbroeck' bevestigd in het Van Straatenarrest. ${ }^{35}$ Blijkens dit arrest is ook sprake van 'dezelfde feiten' indien het materiële feitencomplex niet volledig identiek is. Na 'Van Straaten' is deze lijn doorgezet in het Gasparini-arrest. ${ }^{36}$ Ook hier geeft het Hof van Justitie aan dat sprake is van 'dezelfde feiten' zoals bedoeld in artikel 54 SUO indien blijkt van 'gelijkheid van de materiële feiten, begrepen als het bestaan van een geheel van concrete omstandigheden die onlosmakelijk met elkaar verbonden zijn.' ${ }^{37}$ Voorts blijkt uit de uitspraken

32. HvJEG 9 maart 2006, NJ 2006/488, m.nt. M.R. Mok.

33. HvJEG 9 maart 2006, NJ 2006/488, m.nt. M.R. Mok, r.o. 42. Vgl. HR 13 december 1994, NJ 1995/252.

34. Van Bockel 2010, p. 71.

35. HvJEG 28 september 2006, NJ 2007/56, m.nt. N. Keijzer.

36. HvJ EG 28 september 2006, NJ 2007/57, m.nt. N. Keijzer.

37. HvJ EG 28 september 2006, NJ 2007, 57, r.o. 54, m.nt. N. Keijzer. 
inzake 'Kraaijenbrink'38 en 'Åkerberg Fransson' dat indien beide procedures punitief van karakter zijn, hetgeen kan worden getoetst aan de Bonda-criteria, ${ }^{39}$ die inhoudelijk hetzelfde zijn als de Engel-criteria, ${ }^{40}$ na het onherroepelijk worden van de ene bestraffende sanctie, de andere procedure niet gestart of gestaakt moet worden. Annotator Widdershoven merkt bij het arrest 'Åkerberg Fransson' op dat deze zaak voor het Nederlandse bestuurlijke sanctierecht geen grote gevolgen heeft vanwege de gecodificeerde una via-regelingen in de artikelen 5:44, tweede en derde lid, Awb, en 243, tweede lid, Sv. ${ }^{41}$

\subsubsection{Naar een geïntegreerde benadering?}

Met de uitspraak van het EHRM inzake A. en B. tegen Noorwegen $^{42}$ wordt door het EHRM een andere uitleg gegeven aan het ne bis in idem-beginsel, zoals het deed in het Zolotukhin-arrest en het Maresti-arrest. De feiten in deze zaak zijn als volgt: A. en B. laten na om aangifte te doen bij de Noorse belastingdienst van in 2002 gerealiseerde vermogenswinsten. De fiscale autoriteiten leggen bestuurlijke boetes op ter zake van deze vergrijpen. A. en B. worden eveneens strafrechtelijk vervolgd. De vraag komt op of A. en B. tweemaal vervolgd en gestraft zijn voor hetzelfde strafbare feit en of daarmee inbreuk gemaakt is op het ne bis in idem-beginsel in artikel 4 Protocol 7 EVRM. ${ }^{43}$ In deze zaak staat vast dat sprake is van hetzelfde feit en dat beide sancties kunnen worden aangemerkt als een 'criminal charge'. De rechtsvraag heeft betrekking op de toelaatbaarheid van de dubbele bestraffing van dezelfde gedraging. Cumulatie is volgens het EHRM mogelijk, indien de beide procedures die leiden tot sancties een voldoende nauwe samenhang hebben, zowel inhoudelijk als in tijd. Beide procedures moeten op een voldoende samenhangende manier zijn gecombineerd, waardoor zij een coherent geheel vormen. In dit verband spelen de volgende factoren een rol: 1) er dient sprake te zijn van complementaire doelen, 2) de cumulatie van twee procedures moet voorzienbaar zijn, 3) of de verschillende betrokken autoriteiten samenwerken of overleg hebben en daarbij met name de verzameling van het bewijs en de beoordeling daarvan één keer verrichten en gebruiken in beide procedures, en ten slotte 4) dient het totaalpakket aan sancties evenredig te zijn. ${ }^{44} \mathrm{Op}$ grond van deze criteria overweegt het EHRM dat in casu geen sprake is van een schending van het ne bis in idem-beginsel, zoals dat is neergelegd in artikel 4 Protocol 7 EVRM. ${ }^{45}$ Het gevolg van deze

38. HvJ EG 18 juli 2007, RvdW 2007/739.

39. HvJ EU 5 juni 2012, $A B$ 2012/315, m.nt. R.J.G.M. Widdershoven.

40. EHRM 8 juni 1976, NJ 1978/223.

41. Zie de negende opmerkingen in de annotatie van R.J.G.M. Widdershoven onder HvJ EU 26 februari 2013, AB 2013/131.

42. EHRM 15 december 2016, BNB 2017/14, m.nt. F.J.P.M. Haas; $A B$ 2017/188, m.nt. T. Barkhuysen \& M.L. van Emmerik.

43. Zie ook P. de Haas, 'Voorkomt ons una via-beginsel wel dubbele vervolging en bestraffing?', Tijdschrift voor Formeel Belastingrecht 2017, p. 2-3.

44. Zie de vierde opmerking in de annotatie van T. Barkhuysen \& M.L. van Emmerik onder EHRM 15 december 2016, AB 2017/188.

45. In de zaak Jóhannesson e.a. tegen IJsland heeft het EHRM voor de eerste maal toepassing gegeven aan de vernieuwde visie op het ne bis in uitspraak is volgens Wattel dat 'een una via-stelsel zoals het Nederlandse niet nodig is; een verrekeningsstelsel is veelal voldoende, juist als cumulatie min of meer standaard en daarmee voorzienbaar is en temporeel niet te veel uiteenloopt. ${ }^{46}$

Deze uitspraak van het EHRM dient volgens Hirsch Ballin de gedachtegang over de keuze tussen bestuursrecht en strafrecht te inspireren in de zin dat het debat zou moeten gaan over welke vorm van rechtshandhaving nodig is om - gelet op de beoogde doelen - te kunnen komen tot een efficiënte bestrijding van misdaad en/of onwenselijk gedrag. Zij geeft in dit verband de volgende voorbeelden:

'Daarbij kan worden gedacht aan de combinatie van strafrechtelijke vervolging voor ernstige verkeersdelicten en het opleggen van een alcoholslot of de intrekking van een rijbewijs om herhaling te voorkomen en de maatschappij te beschermen. Ook zou in voorkomende gevallen de meest passende sanctionering kunnen worden gevonden in een combinatie van bestuursrechtelijke sanctionering voor bijvoorbeeld zware overtredingen van sector gerelateerde regelgeving en het afleggen van verantwoording in een strafproces voor bijvoorbeeld fraude. Ieder onderdeel van sanctionering zal zich daarbij dienen te richten op een ander aspect van de gedragingen. Een derde voorbeeld is de combinatie van een strafrechtelijke vervolging van teruggekeerde Jihad-gangers met de oplegging van bestuurlijke maatregelen op grond van dezelfde gedragingen. ${ }^{47}$

Volgens Hirsch Ballin kan de uitspraak van het EHRM inzake A. en B. tegen Noorwegen als inspiratie dienen in het debat over bestuursrecht of strafrecht. In deze discussie zou het volgens haar niet langer moeten gaan om de vraag of bestuurlijke maatregelen als een criminal charge moeten worden aangemerkt, maar of sprake is van een coherent systeem waarbij de verschillende handhavings- en sanctioneringsmogelijkheden evenredig en op elkaar afgestemd zijn.

\subsection{Bevindingen}

Het voorgaande laat zien dat het debat over de keuze tussen bestuursrecht en strafrecht door de Afdeling advisering in gang is gezet en het gebrek aan rechtsbescherming in bestuurlijke punitieve procedures als een probleem wordt aangemerkt. Het debat over de keuze tussen bestuursrecht en strafrecht kan echter niet worden los gezien van ontwikkelingen in 'Europa' met betrekking tot de uitleg van het ne bis in idem-beginsel. Waar de lijn van het EHRM sinds het Zolotukhin-arrest leek te zijn dat artikel 4 Protocol 7 EVRM in de weg staat aan een 'cumulatie van twee bestraffende procedu-

idem-beginsel. Een schending van dit beginsel is aangenomen, omdat sprake is van een beperkte overlap tussen de beide procedures qua tijdsverloop en een grotendeels onafhankelijke bewijsgaring en bewijsbeoordeling. Zie EHRM 18 augustus 2017, appl.nr. 22007/11.

46. P.J. Wattel, 'Bis in idem', NJB 2017/205.

47. M. Hirsch Ballin, 'Strafrecht of bestuursrecht? Beide!', Blogbestuurs recht.nl 7 november 2017 
res over hetzelfde feitelijke gedrag, ook als de ene procedure "bestuurlijk" en de andere "strafrechtelijk" is, en ook als de twee procedures verschillende rechtsgoederen beschermen', ${ }^{48}$ is het EHRM inzake A. en B. tegen Noorwegen duidelijk een andere weg ingeslagen. Thans heeft deze nieuwe uitleg van het ne bis in idem-beginsel nog geen directe gevolgen voor het Nederlandse bestuurlijke sanctierecht en zijn de una via-regelingen van de artikelen 5:44, tweede en derde lid, Awb, en 243, tweede lid, Sv, nog in leven. De vraag is echter wat deze ontwikkeling betekent voor de una via-regeling in het nieuwe Wetboek van Strafvordering.

Ten aanzien van het idee van een geïntegreerde benadering, zoals voorgesteld door Hirsch Ballin, kunnen vraagtekens worden geplaatst. Ten eerste kan erop worden gewezen dat de uitspraak van het EHRM inzake A. en B. tegen Noorwegen ziet op de toepasselijkheid van artikel 4 van het Zevende Protocol EVRM, dat niet door Nederland is geratificeerd. Deze uitspraak is niet direct richtinggevend voor Nederland. Deze kanttekening kan overigens worden genuanceerd vanwege het feit dat de Hoge Raad de jurisprudentie van het EHRM inzake de uitleg van het ne bis in idem-beginsel in de gaten houdt. Zo kan worden gewezen op het overzichtsarrest van de Hoge Raad van 1 februari 2011 over artikel $68 \mathrm{Sr}$, waarin de Hoge Raad overweegt dat de rechtspraak van het EHRM over artikel 4 Zevende Protocol EVRM van belang kan zijn voor de gedachtevorming over de toepassing van artikel $68 \mathrm{Sr}^{49}$ Een sterker argument kan daarom worden gevonden in het wettelijk verankerde una via-beginsel van de artikelen 5:44, tweede en derde lid, Awb, en artikel 243, tweede lid, Sv. Op grond van deze bepalingen is een cumulatie van een bestuurlijke bestraffende sanctie en een strafrechtelijke sanctie niet mogelijk. Zoals Barkhuysen en Van Emmerik terecht in hun annotatie opmerken, heeft de uitspraak van het EHRM inzake A. en B. tegen Noorwegen niet direct gevolgen voor het Nederlandse bestuurlijke sanctierecht. ${ }^{50}$ Deze uitspraak kan de wettelijke verankering van het una via-beginsel niet opzijzetten en biedt de Nederlandse regeling bovendien meer rechtsbescherming dan 'Straatsburg'. Een derde en laatste kanttekening zou geplaatst kunnen worden bij de genoemde voorbeelden van de geïntegreerde benadering van Hirsch Ballin. Deze combinaties zijn alle zonder meer mogelijk, omdat de genoemde bestuurlijke sancties of maatregelen niet zijn aan te merken als bestraffend. Blijkens staande jurisprudentie van de Afdeling kan cumulatie plaatsvinden tussen niet-bestraffende bestuurlijke sancties en strafrechtelijke sancties. ${ }^{51} \mathrm{De}$ Nederlandse una via-regeling belet evenwel een cumulatie tussen de bestuurlijke boete en een strafrechtelijke vervolging/sanctionering.

48. Wattel $2017 / 205$

49. HR 1 februari 2011, NJ 2011/394, m.nt. Y. Buruma; AB 2011/225, m.nt. O.J.D.M.L. Jansen

50. Zie de zesde opmerking in de annotatie van T. Barkhuysen \& M.L. van Emmerik onder EHRM 15 december 2016, AB 2017/188.

51. Zie bijvoorbeeld ABRvS 29 maart 2017, AB 2017/189, m.nt. T. Barkhuysen \& M.L. van Emmerik.
Naar mijn mening is het debat over de keuze tussen bestuursrecht en strafrecht nog immer relevant, met name vanwege het bestaan van de artikelen 5:44, tweede en derde lid, Awb, en 243, tweede lid, Sv. Een belangrijk criterium om te bepalen in hoeverre bestuurlijk of strafrechtelijk dient te worden gereageerd, is het criterium van de ernstige gedraging. Ook de wetgever onderkent het belang ervan, getuige de formulering van enkele bijzondere una via-bepalingen, waarin dit criterium ook daadwerkelijk wordt benoemd. Voorts lijkt de Afdeling advisering het belang van dit criterium te onderschrijven, waar het aangeeft dat, indien hoge boetes dienen te worden opgelegd, het strafrecht het primaat heeft. Waar Hirsch Ballin het strafrecht lijkt te beschouwen als optimum remedium, ${ }^{52}$ dient het strafrecht mijns inziens, indachtig het ultimum remedium-beginsel, ${ }^{53}$ te worden gereserveerd voor ernstige gedragingen. Het bestuursrecht en strafrecht moeten niet als onderling inwisselbaar worden geacht. Dit is ook de gedachte van de wetgever:

'Het punt is van groot belang, omdat het, zoals in het algemeen gedeelte van dit hoofdstuk van deze memorie van toelichting is uiteengezet, nogal eens voorkomt dat de wet op overtreding van een voorschrift zowel een strafsanctie als een bestuurlijke boete stelt. In dat geval zal de overheid moeten kiezen. Het gaat er niet slechts om, dat geen twee straffen worden opgelegd. Ook moet worden voorkomen dat iemand nodeloos tweemaal in een sanctieprocedure wordt betrokken voor dezelfde overtreding ("nemo debet bis vexari").'54

Blijkens de wetgeschiedenis van de artikelen 5:44 Awb en 243, tweede lid, Sv, dient de keuze tussen bestraffende bestuurlijke en strafrechtrechtelijke handhaving ten aanzien van hetzelfde moment op een gegeven moment definitief te zijn. Van een optimum remedium-gedachte heeft de wetgever geen blijk gegeven. Wel blijkt dat de wetgever van mening is dat criteria dienen te worden ontwikkeld, die neerslag krijgen in een convenant en/of in vervolgingsrichtlijnen van het Openbaar Ministerie. Daarnaast is rekening gehouden met de mogelijkheid dat de wetgever zelf criteria voor de keuze tussen bestuursrecht en strafrecht formuleert. ${ }^{55}$ Om uitdrukking te geven aan het ultimum remedium-karakter van het strafrecht zou uniformering tussen de algemene una

52. Kamerstukken // 2015/16, 29 279, nr. 334, p. 12: 'In de "optimumremediumgedachte" is van belang dat voor een reactie op ongewenst gedrag de werkzame, werkbare en passende middelen beschikbaar zijn en dat van geval tot geval voor een bepaald middel of een mix van middelen wordt gekozen. In concrete casuïstiek zal het "optimum remedium" betekenen dat de professionals in samenwerking met inzet van hun specifieke disciplines concluderen tot de meest passende reactie op een misdrijf: een betekenisvolle afdoening richting slachtoffer, dader en maatschappij.'

53. In het verband van de integrale aanpak van misdaad wordt het strafrecht steeds meer de betekenis van 'optimum remedium' toegedicht. Vanuit een rechtsstatelijk perspectief zijn de gevolgen van een dergelijke visie echter nog niet ten gronde doordacht.

54. Kamerstukken // 29702, nr. 3, p. 137-139

55. Kamerstukken // 29702, nr. 3, p. 137-139 
via-bepaling van artikel 5:44 Awb en de bijzondere bepalingen, zoals artikel 55 Meststoffenwet, dienen te worden bewerkstelligd, door het criterium van de ernstige gedraging neer te leggen in artikel 5:44 Awb.

\section{Een voorstel tot codificering van het una via-beginsel}

\subsection{Het una via-beginsel in het nieuwe Wetboek van Strafvordering}

Het Wetsvoorstel tot vaststelling van Boek 3 van het nieuwe Wetboek van Strafvordering handelt over de beslissingen omtrent de vervolging. Uit het wetsvoorstel blijkt dat de huidige artikelen 167, tweede lid, en 243, tweede lid, $\mathrm{Sv}$, worden vervangen door artikel 3.1.4 van het nieuwe Wetboek van Strafvordering. Uit het eerste lid van artikel 3.1.4 blijkt dat na een kennisgeving van niet-vervolging de verdachte niet kan worden vervolgd voor hetzelfde feit, behoudens sprake is van nieuwe bezwaren (artikel 3.1.4, eerste lid, sub a) of indien het gerechtshof een beklag gegrond heeft verklaard en de opsporing van het feit waarop de klacht betrekking heeft of vervolging van de verdachte beveelt (artikel 3.1.4, eerste lid, sub b). Nergens blijkt hoe dient te worden gereageerd op een situatie waarbij een bestuurlijke boete wegens hetzelfde feit is opgelegd door een bestuursorgaan. Gezien de door de minister verwoorde doelstellingen van 'modernisering', te weten:

'het opnemen van een duidelijke regeling van de bevoegdheden en procespositie van de verschillende deelnemers aan de strafrechtspleging, waarbij voorzien is in een evenwichtig stelsel van rechtswaarborgen en een juiste afweging van de verschillende belangen van deze procesdeelnemers', ${ }^{56}$

is het merkwaardig dat geen enkele aandacht is besteed aan een regeling betreffende de keuze tussen bestuursrecht en strafrecht in modernisering van Strafvordering. Deze situatie wordt thans geregeld door het bepaalde in artikel 243, tweede lid, Sv, maar tot op heden is aan deze problematiek geen aandacht besteed in de vaststellingswetten. ${ }^{57} \mathrm{Om}$ in deze omissie te voorzien dient artikel 3.1.4 te worden aangevuld met het bepaalde in artikel 243, tweede lid, Sv. Er zou gedacht kunnen worden aan een toevoeging van artikel 3.1.4. Gedacht kan worden aan een toevoeging van een vijfde lid, dat hetzelfde luidt als het huidige artikel 243, tweede lid, Sv.

'Indien terzake van het hetzelfde (toevoeging: BvdV) feit aan de verdachte een bestuurlijke boete is opgelegd, dan wel een mededeling als bedoeld in artikel

56. Kamerstukken I/ 2015/16, 29279, 278, p. 47

57. Ook Kooijmans heeft in een breder perspectief opgemerkt dat het voorstel ten aanzien van de vervolging door het Openbaar Ministerie nog prematuur en onvoldoende is uitgewerkt. Zie T. Kooijmans, 'Het Openbaar Ministerie en de vervolging in het nieuwe Wetboek van Strafvordering', RMThemis 2017, p. 291-302.
5:50, tweede lid, onderdeel a, van de Algemene wet bestuursrecht is verzonden, heeft dit dezelfde rechtsgevolgen als een kennisgeving van niet verdere vervolging.'

Op deze wijze kan het una via-beginsel in het nieuwe Wetboek van Strafvordering een plaats krijgen. Zoals uit het voorgaande is gebleken verdient het om meerdere redenen aanbeveling om het una via-beginsel een plaats te geven in het nieuwe Wetboek van Strafvordering. De formulering van een una via-regeling in het nieuwe Wetboek van Strafvordering kan overigens door de wetgever eveneens worden aangegrepen om het bepaalde in artikel 5:44 Awb tegen het licht te houden.

\subsection{Het una via-beginsel in de Awb}

Zoals eerder is gebleken, zijn de algemene una via-bepaling van de Awb en de una via-bepalingen in enige bijzondere bestuursrechtelijke wetten op verschillende wijzen geformuleerd. Ten aanzien van de keuze tussen bestuursrecht en strafrecht zou het ultimum remediumkarakter van het strafrecht meer kunnen worden benadrukt dan thans het geval is. Zo wordt in de una viabepaling van artikel 55 Meststoffenwet expliciet gewezen op de ernst van de overtreding. Om de una viabepalingen in de bestuursrechtelijke wetten meer op elkaar te laten aansluiten en om tegenwicht te bieden tegen de opvatting van het strafrecht als optimum remedium, zou ervoor kunnen worden gekozen om het tweede lid van artikel 5:44 Awb, waarin de voorlegplicht is geregeld, aan te passen. In het huidige artikel 5:44 Awb wordt namelijk niet gewezen op de ernst van de overtreding/gedraging. Voorgesteld kan worden om artikel 5:44, tweede lid, Awb, te integreren met de formulering in de bijzondere bestuursrechtelijke una via-bepalingen. Het tweede lid van artikel 5:44 Awb zou als volgt kunnen worden aangepast:

'Indien de gedraging tevens een strafbaar feit is, de ernst van de overtreding of de omstandigheden waaronder zij is begaan daartoe aanleiding geven, wordt zij aan de officier van justitie voorgelegd, tenzij bij wettelijk voorschrift is bepaald, dan wel met het openbaar ministerie is overeengekomen, dat daarvan kan worden afgezien.'

Een dergelijke formulering van artikel 5:44, tweede lid, Awb, doet recht aan het ultimum remedium karakter van het strafrecht. Ten aanzien van de keuze tussen bestuursrecht en strafrecht dient in voorkomende gevallen aandacht te worden geschonken aan het criterium van de ernstige gedraging. Bovendien wordt meer uniformiteit bereikt tussen de voorlegplicht uit de algemene una via-bepaling en enige bijzondere bestuursrechtelijke una via-bepalingen. Voorts wordt voorkomen dat het bestuursrecht en strafrecht als onderling inwisselbaar worden aangemerkt, zoals uit de optimum remediumgedachte naar voren lijkt te komen. De discussie dient naar mijn mening nog immer te gaan over de keuze tussen bestuursrecht en strafrecht. In ieder geval dient 
het niet primair te gaan om de vraag over welke vorm van rechtshandhaving nodig is om - gelet op de beoogde doelen - te kunnen komen tot een efficiënte bestrijding van misdaad en/of onwenselijk gedrag. Een dergelijke discussie doet naar mijn mening onvoldoende recht aan het ultimum remedium-karakter van het strafrecht.

\section{Conclusie}

Thans is een belangrijke wetgevingsoperatie gaande, waarbij het Wetboek van Strafvordering wordt herzien. Opmerkelijk genoeg wordt in de vaststellingswetten op geen enkele wijze aandacht besteed aan de keuze tussen bestuurlijke en strafrechtelijke handhaving. In artikel 243 , tweede lid, van het huidige Wetboek van Strafvordering en in artikel 5:44 Awb, zijn de regels omtrent deze kwestie geregeld. Parallel aan de modernisering van het Wetboek van Strafvordering zal het kabinet zich gaan buigen over de vervanging van de thans geldende criteria ten aanzien van de keuze tussen bestuursrecht en strafrecht, namelijk de 'open context' en 'gesloten context'. Het debat over deze keuze tussen beide handhavingsstelsels is dermate actueel, het speelt zowel op nationaal als op het niveau van het EHRM, dat ook in het verband van de modernisering van het Wetboek van Strafvordering aandacht moet worden besteed aan dit onderwerp. Om het una via-beginsel een plaats te geven in het nieuwe Wetboek van Strafvordering wordt voorgesteld om het bepaalde in artikel 243, tweede lid, Sv, te transponeren naar artikel 3.1.4, vijfde lid, van het nieuwe Wetboek van Strafvordering. Daarnaast zou de wetgever de mogelijkheid kunnen aangrijpen om artikel 5:44, tweede lid, Awb, aan te passen, door het criterium van de ernstige gedraging een plaats te geven, zodat ten aanzien van de keuze tussen bestuursrecht en strafrecht, het ultimum remedium-karakter van het strafrecht wordt benadrukt. Op deze wijze kan tegenwicht worden geboden aan de opvatting van het strafrecht als optimum remedium. 